\title{
Desain Produk Furniture Dari Material Komposit Limbah Styrofoam
}

\author{
Muhammad Rizki R \\ Program Studi Desain Produk, Universitas Pembangunan Jaya \\ Tangerang Selatan, Banten 15413, Indonesia \\ Email korespondensi: muhammad.rizki@student.upj.ac.id
}

Received 22 December 2020, Revised 25 March 2021, Accepted 21 May 2021

\begin{abstract}
Styrofoam is a material that is easy to uses and founded in daily life. That materials also have a low price. Therefore, Styrofoam is often used starting from packing of food and goods. The waste of this material is spread in many quantities. It isn't easy to decompose just like plastic. Therefore, recycling the material to become another product and reduce the waste of styrofoam is a must. The composite method can be selected to recycle styrofoam. This study was carried out by materials experiment in making composite material By mixing styrofoam and concrete. The composite materials can be used for developing a new product such as furniture. The benefit is added value of furniture products and reduce the environmental impact.
\end{abstract}

Keywords: Styrofoam, Concret, Material, Furniture, Waste

\begin{abstract}
Abstrak - Styrofoam merupakan bahan yang mudah digunakan dan ditemukan dalam kehidupan sehari-hari. Bahan tersebut juga memiliki harga yang rendah. Oleh karena itu, styrofoam sering digunakan mulai dari pengemasan makanan dan barang. Limbah bahan ini tersebar dalam jumlah yang banyak. Tidak mudah terurai dibandingkan bahan lain seperti plastik. Oleh karena itu, mendaur ulang bahan tersebut menjadi produk lain untuk mengurangi limbah styrofoam adalah suatu keharusan. Metode komposit dapat dipilih untuk mendaur ulang styrofoam. Penelitian ini dilakukan dengan eksperimen material berupa pembuatan material komposit dengan cara mencampurkan styrofoam dan beton. Material komposit dapat digunakan untuk mengembangkan produk baru seperti furniture. Manfaatnya dapat menambah nilai produk furnitur dan mengurangi dampak lingkungan.
\end{abstract}

Kata Kunci: Styrofoam, Beton, Material, Furniture, Limbah

\section{PENDAHULUAN}

Styrofoam/Polystyrene merupakan salah satu jenis bahan plastik yang sangat ringan, kaku, tembus cahaya, dan murah. Awalnya bahan ini didesain untuk melindungi barang elektronik, seperti: TV, radio, kulkas, dan lain-lain dari benturan benda keras. Karena styrofoam mudah diperoleh, praktis, murah, anti bocor, serta tahan suhu panas dan dingin, bahan tersebut selanjutnya dimanfaatkan sebagai pengemas makanan. Material ini bersifat non-daur ulang dan nonbiodegradable (Fitidarini, N., Damanhuri, E. 2011). Material tersebut dirancang untuk sekali pakai. Dibutuhkan beberapa ratusan tahun agar styrofoam dapat terurai secara alami di lingkungan terbuka.

Di perkotaan, styrofoam hanya terurai menjadi potongan-potongan kecil yang akhirnya menjadi sampah dan mencemari air laut, tanah, ruang terbuka, dan saluran drainase. Material ini menyumbang kontribusi besar sebagai sampah yang tidak dapat didaur ulang di perkotaan. Penelitian yang dilakukan oleh Lembaga Ilmu Pengetahuan Indonesia (LIPI) di 18 kota utama Indonesia menemukan 0,27 juta ton hingga 0,59 juta ton sampah masuk ke laut Indonesia selama kurun waktu 2018. Sampah yang paling banyak ditemukan adalah sampah styrofoam (Republika. 2019).

Limbah styrofoam sampai saat ini masih belum dapat diatasi pemusnahannya secara maksimal, mengingat bahan tersebut tidak mudah diuraikan oleh alam. Apabila dilakukan pemusnahan dengan cara pembakaran, akan mengeluarkan berbagai zat berbahaya termasuk benzena yang dilepas ke udara (Wirahadi, M. 2017). Hal ini akan berakibat pada pencemaran udara sehingga menimbulkan polusi dan membahayakan bagi pernapasan manusia.

Berbagai penelitian untuk mendaur ulang styrofoan dan memanfaatkan ulang bahan tersebut menjadi bahan siap pakai untuk pembuatan produk, sudah dilakukan, seperti pengolahan limbah styrofoam menjadi bahan campuran pembuatan batako dan dinding rumah tinggal (Winarno, H. R., Pujantara, R. 2015). Cara yang dilakukan tersebut menggunakan metode komposit dimana limbah styrofoam dipadukan dengan campurkan pasir dan semen. 
Berdasarkan metode tersebut, pengembangan lebih lanjut dapat dilakukan untuk memanfaatkan limbah styrofoam yang tidak terbatas hanya untuk pembuatan batako saja. Dalam penelitian ini, kami melakukan proses eksperiment penggunaan bahan komposit dari paduan limbah styrofoam dan semen untuk diaplikasikan menjadi produk furniture.

Dengan memanfaatkan limbah stryofoam untuk penggunaan yang lebih luas, diharapkan dapat membantu untuk mengurangi dampat negatif terhadap pencemaran lingkungan yang disebabkan dari bahan tersebut.

\section{METODE PENELITIAN}

Lokasi penelitian dan pengambilan sampel bahan styrofoam yang akan diproses dengan menggunakan metode komposit, difokuskan pada daerah perkotan, dimana limbah styrofoam sebagian besar tersebar di wilayah tersebut.

Proses pembuatan material komposit dilakukan dengan pendekatan eksperimen, tahap awal penelitian yaitu melakukan ujicoba untuk mendapatkan komposisi yang ideal dari paduan komposit antara material styrofoam dan semen yang kemudian dapat dipakai untuk pembuatan prototype produk furniture (kursi).

Selanjutnya akan menerapkan metode pendekatan EOQ (Economic Order Quantity) untuk tujuan kalkukasi kebutuhan limbah styrofoam dan menentukan kuantitas dan nilai ekonomis produksi untuk pembuatan produk furniture. Kemudian akan dilakukan studi terhadap calon pengguna melalui kuesioner online. Dari hasil kuesioner akan dilakukan analisa terhadap ketertarikan calon pengguna terhadap produk ini.

\section{HASIL PENELITIAN DAN ANALISIS}

Tahap awal proses eksperimen dilakukan dengan membuat empat sampel bahan komposit yang dibuat dengan komposisi perbandingan paduan bahan styrofoam dan semen yang berbeda (Tabel 1). Komposisi bahan yang digunakan merujuk kepada standar campuran yang umumnya digunakan untuk bahan beton yaitu mengcu kepada SNI 7656-2012 dan ASTM C 136-06 mengenai persyaratan untuk perencanaan beton (Arman, A. 2018).

Dari keseluruhan sampel bahan yang telah dibuat, selanjutkan akan dilakukan komparasi terhadap empat jenis sampel tersebut. Hasilnya akan diidentifikasikan jenis sampel yang paling ideal sebagai material dasar pembuatan produk furniture.

Tabel 1. Komposisi paduan bahan styrofoan dan semen

\begin{tabular}{cccccc}
\hline Sampel & Semen & Air & Pasir & Styrofoam & Udara \\
\hline 1 & $7 \%$ & $16 \%$ & $25 \%$ & $51 \%$ & $1 \%$ \\
2 & $15 \%$ & $21 \%$ & $30 \%$ & $31 \%$ & $3 \%$ \\
3 & $20 \%$ & $20 \%$ & $35 \%$ & $20 \%$ & $5 \%$ \\
4 & $30 \%$ & $20 \%$ & 0 & $50 \%$ & 0 \\
\hline
\end{tabular}

Hasil eksperiment dari empat jenis sampel bahan yang telah dilakukan, menunjukkan hasil kekuatan bahan yang berbeda-beda. Sampel 1, menghasilkan bahan yang getas dan mudah patah, permukaan bahan sangat kasar. Sampel 2, permukaan kasar dan bahan styrofoam tidak melekat secara sempurna dengan bahan semen. Sampel 3, menghasilkan permukaan halus, padat dan berbobot berat. Sampel 4, bobot lebih ringan dibandingkan sampel yang lain, padat dan permukaan sedikit kasar. Hasil eksperiment dapat dilihat pada tabel 2.

Tabel 2. Hasil eksperimen pembuatan sampel bahan

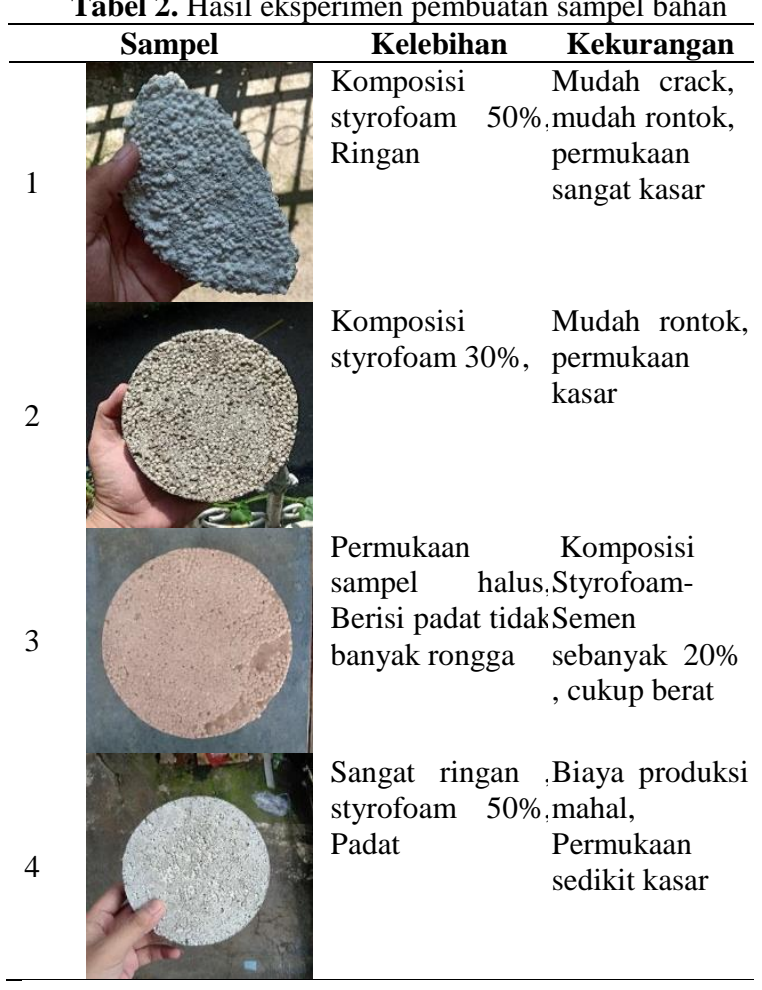

Selanjutnya dilakukan uji pengaruh cuaca terhadap kondisi permukaan bahan dan kekuatan dalam menahan beban. Hasil uji coba tersebut ditampilkan pada tabel 3. Hasilnya dapat disimpulkan, untuk sampel 4 memiliki berat akhir sekitar 200 gram atau 1/3 dari beton murni pada umumnya. Penggunaan limbah styrofoam mencapai $50 \%$. Ketahanannya terhadap cuaca dan beban hingga 95kg. Kondisi ini menjadikan sampel 4 sangat ideal untuk diaplikasikan sebagai bahan pembuatan produk furniture.

Tabel 3. Hasil uji cuaca dan beban

\begin{tabular}{|c|c|c|}
\hline Sampel Massa & Uji Cuaca & Uji Beban \\
\hline $200 \mathrm{gr}$ & $\begin{array}{ll}\text { Styrofoam } & \\
\text { terkelupas, } & \text { warna } \\
\text { gelap } & \text { karena } \\
\text { menyerap air } & \end{array}$ & $\begin{array}{l}\text { Retak pada saat di } \\
\text { berikan beban } 3 \mathrm{~kg}\end{array}$ \\
\hline $400 \mathrm{gr}$ & $\begin{array}{l}\text { Styrofoam sedikit } \\
\text { terkelupas, ringkih, } \\
\text { warna gelap karena } \\
\text { menyerap air }\end{array}$ & $\begin{array}{l}\text { Retak rambut pada } \\
\text { saat diberikan } \\
\text { beban } 23 \mathrm{~kg}\end{array}$ \\
\hline $375 \mathrm{~g}$ & $\begin{array}{ll}\text { Aman \& Kuat, warna } \\
\text { gelap karena } \\
\text { menyerap air }\end{array}$ & $\begin{array}{l}\text { Tidak retak pada } \\
\text { saat diberikan } \\
\text { beban } 95 \mathrm{~kg}\end{array}$ \\
\hline
\end{tabular}


Aman \& Kuat, warna Tidak retak pada

4 200gr gelap karena saat diberikan menyerap air beban $95 \mathrm{~kg}$

Tahapan penelitian selanjutnya yang dilakukan yaitu melakukan proses pembuatan prototype produk kursi. Proses pembuatan prototype dimulai dengan proses sketsa desain dari produk kursi yang akan dibuat (Gambar 1). Selanjutnya dibuat gambar detail dari desain yang akan dibuat (Gambar 2).

Proses pembuatan prototype produk dimulai dengan pembuatan cetakan atau bekisting. Bekisting adalah konstruksi bersifat sementara yang merupakan cetakan untuk menentukan bentuk dari konstruksi yang menggunakan bahan beton. Bekisting ini digunakan sebagai cetakan sementara yang digunakan untuk menahan beton selama beton dituang dan dibentuk sesuai dengan bentuk yang diinginkan (Abdul, M., Trijeti. 2013).

Bekisting yang digunakan pada penelitian ini dibuat dari bahan fiber, bahan ini lebih tahan lama dan dapat digunakan berulang kali (Gambar 3). Selanjutnya proses pembuatan prototype diawali dengan cara membuat campuran komposit dari material styrofoam dan beton, kemudian dituangkan kedalam bekisting yang sudah dibuat (Gambar 4).

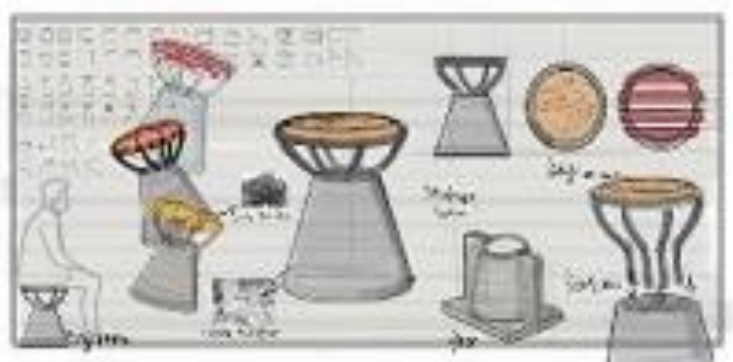

Gambar 1. Sketsa desain

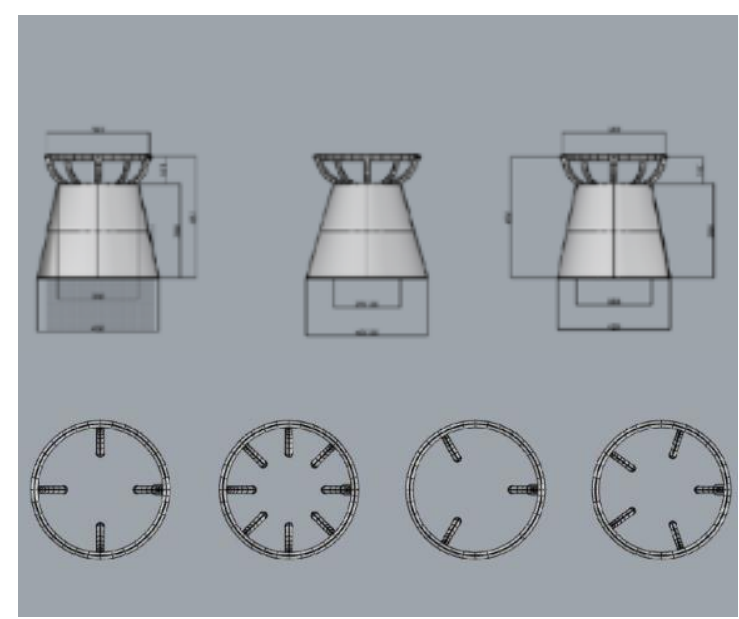

Gambar 2. Gambar detail desain furniture
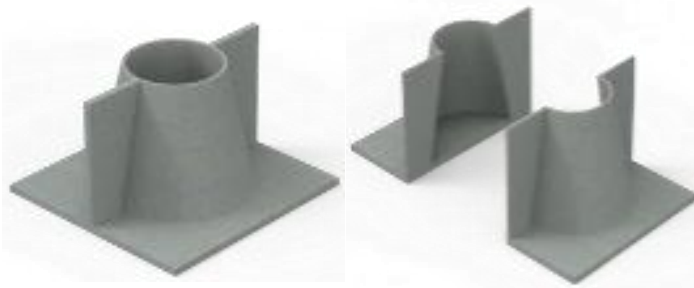

Gambar 3. Bekisting untuk prototype produk

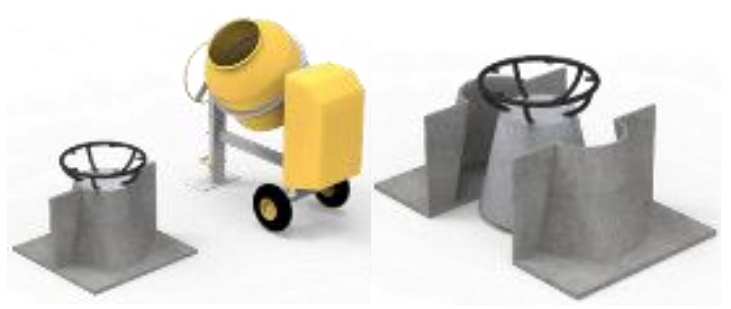

Gambar 4. Proses pencetakan

Setelah hasil campuran styrofoam dan beton dilepas dari bekisting, selanjutnya dapat dilakukan proses finishing. Proses ini dilakukan dengan cara menghaluskan permukaan beton dan dilanjutkan dengan proses penambalan untuk permukaan beton yang berongga akibat terperangkapnya udara didalam beton pada saat proses pencampuran material. Proses penghalusan dilakukan dengan menggunakan gerinda-amplas.

Proses akhir yaitu finishing, dengan cara melakukan coating atau pelapisan permukaan dengan cara disemprot menggunakan alat sprayer. Tahapan ini berguna agar permukaan beton dan rangka dapat lebih tahan lama terhadap pengaruh perubahan cuaca dan suhu pada saat produk ditempatkan di lingkungan terbuka atau diluar ruangan. Hasil akhir dari proses pembuatan prototype dan finishing produk ditampilkan pada gambar 5, kondisi penggunaan prototype produk disimulasikan pada gambar 6.

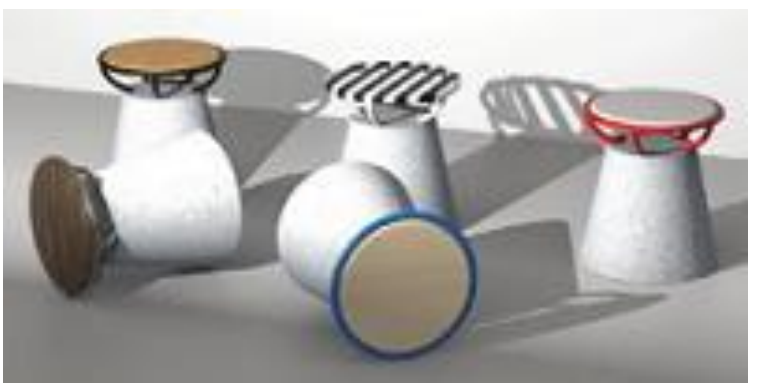

Gambar 5. Hasil akhir prototype produk furniture

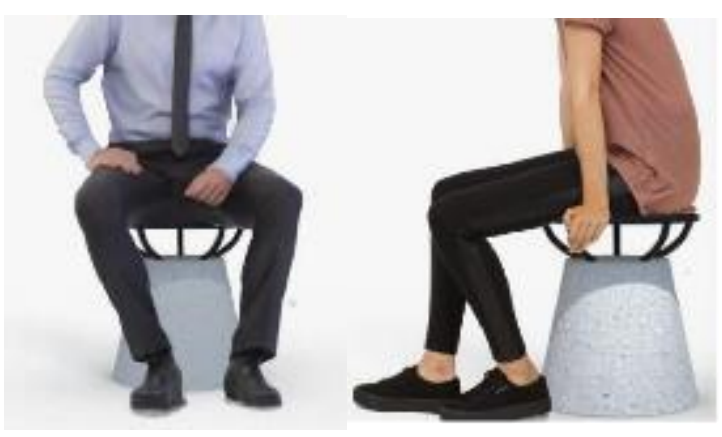

Gambar 6. Penggunaan prototype produk furniture 
Untuk melakukan produksi secara komersial, selanjutnya menerapkan perhitungan degan pendekatan metode EOQ (Economic Order Quantity) untuk tujuan kalkukasi kebutuhan limbah styrofoam dan menentukan jumlah ekonomis untuk proses produksi kursi, selain itu metode ini dapat dipakai untuk meningkatkan efisiensi persediaan bahan baku dalam proses produksi (Rahardyan, D. P. 2012). Rumus perhitungan EOQ yang digunakan yaitu sebagai berikut:

$$
E O Q=\sqrt{ }((2 . R . S) /(P . I))
$$

Diasumsikan bahwa dalam sebuah proses produksi pembuatan furniture berbahan beton, membutuhkan campuran limbah styrofoam sebanyak $1 \mathrm{~kg}$ untuk pembuatan 1 unit produk furniture. Dengan menggunakan asusmsi harga $1 \mathrm{~kg}$ limbah styrofoam Rp. 6.000,-. dan biaya pengiriman produk dengan berat total bahan $1 \mathrm{~kg}$ adalah Rp. 15.000,maka perhitungan jumlah pemesan ekonomis untuk produk furniture tersebut menggunakan pendekatan metode EOQ yaitu sebagai berikut:

$$
\begin{aligned}
& E O Q= \\
& (2 \times 2,880,000 \times 300,000) /(6,000 \times 25 \%)= \\
& 33,941
\end{aligned}
$$

Dari hasil perhitungan diatas maka dapat dihitung kebutuhan untuk pemesanan adalah $2.880 .000: 33,941=85$ kali pemesanan dalam satu tahun. Jika satu tahun sama dengan 360 hari maka jangka waktu pemesanan adalah $360: 85=4$ hari sekali. Berdasarkan perhitungan tersebut, produk furniture ini, dapat dibuat dengan jumlah minimum yang memenuhi nilai ekonomis produksi.

Dari hasil penelitian ini, diharapkan produk furniture yang dihasilkan memiliki nilai visual dan fungsi yang lebih baik dari produk sejenis yang terbuat dari bahan beton cor yang umumnya memiliki tampilan visual dengan bentuk masif dengan bobot yang berkesan berat dan kaku (Angga, W. 2015).

\section{KESIMPULAN}

Berdasarkan hasil dari penelitian yang sudah dilakukan ini, dapat disimpulkan bahwa produk furnitur dapat menggunakan bahan komposit campuran styrofoam dan semen. . Selain itu, produk harus mempertimbagkan aspek lingkungan yang ditinjau dari penggunaan bahan dan proses produksinya.

Dengan menerapkan metode komposit dari material beton dengan campuran limbah styrofoam sebagai material utama membuat produk, hasil akhir yang didapat yaitu bertujuan untuk meminimalisir limbah material yang tidak terpakai. Selain itu pembuatan produk ini dapat menjadi solusi untuk pengembangan produk dimana material beton tidak hanya digunakan pada bangunan saja tetapi dapat di padukan dengan bahan lain yang dapat dimanfaatkan sebagai material dasar untuk berbagai macam produk seperti untuk produk furniture.

Protoype yang dihasilkan ini, memiliki kehandalan untuk penggunaan outdoor yang tahan cuaca, awet, serta nyaman digunakan. Dengan penggunaan limbah styrofoam sebagai bahan dasar pembuatan produk, bahan yang tidak terpakai dan berbahaya bagi lingkungan dapat diolah dan diproses menjadi sebuah produk yang bermanfaat dan diharapkan menjadi salah satu solusi untuk mengatasi pencemaran lingkungan dari limbah styrofoam.

Penelitian lebih lanjut dapat dilakukan untuk pengembangan dan inovasi penggunaan limbah material styrofoam yang dapat diaplikasikan untuk berbagai macam jenis kebutuhan dan produk fungsional lainnya.

\section{PENGAKUAN}

Artikel ini adalah hasil penelitian tugas akhir yang dilakukan oleh mahasiswa dari program studi desain produk Universitas Pembangunan Jaya.

\section{DAFTAR PUSTAKA}

Arman, A. (2018). Kajian Kuat Tekan Beton Normal Menggunakan Standar SNI 7656-2012 Dan ASTM C 136-06, Rang Teknik Journal, 1(2), 142-148.

Angga, W. (2015). Estetika Pada Desain Bangku Taman Untuk Anak Di Kota Surabaya (Sebuah Tela'ah Desain Pada Struktur dan Material Untuk Model Bangku Taman Khusus Anak) Seminar Nasional Sains dan Teknologi Terapan III 2015. Pp.603-616.

Abdul, M., Trijeti. (2013). Analisis Bekisting Metode Semi Sistem dan Metode Sistem Pada Bangunan Gedung. Jurnal Konstruksia, 4(2), 27-38.

Fitidarini, N., Damanhuri, E. (2011). Timbulan Sampah Styrofoam di Kota Bandung. Jurnal Teknik Lingkungan, 17(2), 87-97.

Rahardyan, D. P. (2012). Efisiensi Metode Economical Order Quantity (Eoq) Dalam Pengambilan Keputusan Pembelian Bahan Baku dan Pengaruhnya Terhadap Total Biaya Pembelian Pada PT Amitex (Amanah Mitra Industri) Buaran Kabupaten Pekalongan. Skripsi. Fakultas Ekonomika dan Bisnis Universitas Diponegoro Semarang.

Wirahadi, M. (2017). Elemen Interior Berbahan Baku Pengolahan Sampah Styrofoam dan Sampah Kulit Jeruk. Jurnal Intra 5(2), 144-153.

Winarno, H. R., Pujantara, R. (2015). Pengaruh Komposisi Bahan Pengisi Styrofoam Pada Pembuatan Batako Mortar Semen Ditinjau Dari Karakteristik dan Kuat Tekan. Indonesian Journal of Fundamental Sciences 1(1), doi: 10.26858/ijfs.v1i1.2114.

Republika, (2019). LIPI: 0,59 Juta Ton Sampah Berakhir di Laut Indonesia, https://republika.co.id/berita/ q2ef65463/lipi-059-juta-ton-sampah-berakhir-di-autindonesia [12 Desember 2019]. 